\title{
ANÁLISE DOS ELEMENTOS ATÍPICOS DO SISTEMA DE ESGOTO - SEPARADOR ABSOLUTO - NA CIDADE DO RIO DE JANEIRO
}

\author{
Alexandre Pessoa Dias ${ }^{1}$ \\ Thereza Christina de Almeida Rosso ${ }^{2}$
}

\begin{abstract}
Resumo - Este trabalho analisa a problemática das interconexôes entre os sistemas de esgotamento sanitário e de drenagem pluvial e seus impactos sobre as coleçóes hídricas da Cidade do Rio de Janeiro, verificandose até que ponto o tipo de sistema oficialmente concebido - separador absoluto - de fato contempla suas funçóes sanitárias e ambientais de coleta, transporte e destino final adequado dos esgotos sanitários. Procurase trabalhar a hipótese de que muitas das soluçóes adotadas para a despoluição dos corpos hídricos estáo gradualmente descaracterizando e desqualificando as vantagens deste sistema, o que indica a necessidade de mudança de direção e da trajetória das intervenções de controle da poluição no Rio de Janeiro, por uma inadiável questão de responsabilidade socioambiental.
\end{abstract}

Palavras-chave: águas urbanas; esgotos sanitários, drenagem pluvial.

Abstract - This paper examines the issue of the interconnectivity between sanitary and rain drainage systems and its impacts on water collections of City of Rio de Janeiro, with the extent to which type of system formally designed - separated sewer - in fact contains their health and environmental functions of collection, transport and adequate sewage disposal. It is discussed the hypothesis that many of the solutions adopted for cleaning water bodies gradually weak and disqualifies the advantages of this system, indicating the need for changing direction and trajectory to pollution control interventions in Rio de Janeiro by an urgent matter of environmental and social responsibility.

Key words: urban water, sanitary sewage, rain drainage.

\footnotetext{
${ }^{1}$ Engenheiro civil, com ênfase em Engenharia Sanitária pela UERJ. Mestre em Engenharia Ambiental pelo Programa de Pós-Graduação em Engenharia Ambiental (PEAMB/FEN/UERJ). Engenheiro de Bio-Manguinhos/Fiocruz. Professor convidado da ENSP e da EPSJV/Fiocruz. Professor substituto da FAU/UFRJ. Endereço: Rua Mearim 40, apto 401 - Grajaú - Rio de Janeiro - RJ - CEP: 20561-070 Brasil - Tel: (21) 3563-0236 - e-mail: apessoa@bio.fiocruz.br.

2 Engenheira Civil, M.Sc. em Engenharia Civil, D.Sc. em Engenharia Oceânica, Prof. Adjunto, VII PEAMB/ENG/UERJ. Endereço: Rua São Francisco Xavier, 524, 5․ Andar, sala 5008, Bloco E, Maracanã, Rio de Janeiro, RJ,CEP. 20550-900, e-mail: rosso@uerj.br.
} 


\section{INTRODUÇÃO}

Inúmeros projetos de ocupação territorial, obras de engenharia e implantação de tecnologias geram graves conflitos de uso dos recursos naturais, provocando impactos ambientais, econômicos e sociais. A questáo ambiental está incorporada à Engenharia, uma vez que esta é responsável direta por significativas transformaçóes da natureza ao mesmo tempo em que é capaz de valer-se de diversas ciências para desenvolver técnicas apropriadas visando minimizar os impactos das ações antrópicas sobre o meio ambiente. Dentre elas encontram-se as açóes do saneamento que devem incorporar conceitos e modelos ecológicos para efetivamente obter resultados profícuos. Estas mesmas açóes devem ser analisadas em suas mínimas conseqüências, de maneira a permitir o desenvolvimento de todo um substrato tecnológico capaz de impedir ou neutralizar a introduçáo de resultados secundários nocivos.

Enquanto estiverem distantes os campos teórico e prático das intervençóes de saneamento ambiental, os resultados para o controle da poluição urbana continuarão sendo precários e incertos. Com o nível de saturação das cidades, a problemática da poluição e o seu não adequado equacionamento passam a ser fatores limitantes para o desenvolvimento da urbe. Para cumprirem seus objetivos sanitários, as intervençóes de saneamento devem atender aos condicionantes ambientais a fim de garantir efetivamente boas condições de saúde pública.

Nesse contexto, as modificações antrópicas devem se dar de "forma ecológica". Ao introduzir elementos artificiais ocupando espaços, criando novas estruturas e novos meios, o homem deve analisar previamente e de forma global as implicaçôes sobre o ecossistema urbano. A não atenção aos limites críticos de manipulaçáo dos sistemas ecológicos, com evidentes prejuízos à saúde e à qualidade de vida gera também uma problemática em termos de limitação de recursos naturais.

Em grandes centros urbanos estas relações são bem evidenciadas, pois os sistemas naturais, artificiais, e seminaturais se relacionam e interagem de forma singular, pelas suas extensóes e intensidade.

Os sistemas de esgotamento da Cidade do Rio de Janeiro é um bom exemplo. A grandiosidade da escala dos sistemas de saneamento implanta- dos, a falta de recursos necessários à sua operação e manutenção adequadas, as dificuldades decorrentes das alternativas tecnológicas adotadas, associadas às especificidades da cidade, resultaram em enorme complexidade e vulnerabilidade, na gestão das águas urbanas. Ao longo do processo de urbanização, inúmeras dificuldades de operacionalizaçáo dos sistemas de esgotamento sanitário e pluvial se acumularam. O aporte de esgoto sanitário se dá praticamente na totalidade dos corpos hídricos da cidade e sob diversas formas. Dentre as principais limitaçóes técnicas dos sistemas de esgotos, destaca-se a interconexão - situação indesejável de lançamento de efluentes sanitários no sistema de drenagem pluvial, e vice-versa - que, por sua extensão e intensidade, torna os sistemas extremamente vulneráveis. Esta situação além de contaminar os sistemas de drenagem pluvial e de seus corpos receptores lesa os ecossistemas e submete as populaçôes a riscos epidemiológicos.

A interconexáo entre os sistemas de esgotos é uma das principais fontes de poluição dos corpos receptores nas cidades brasileiras, entretanto na maioria das vezes é negligenciada pelo poder público e pelas concessionárias. Em sentido inverso, a introduçáo, durante as chuvas, de quantidade significativa de contribuição indevida às redes coletoras de esgoto sanitário, compromete sua capacidade hidráulica original, incorpora resíduos comumente encontrados nas águas pluviais (areia, galhos, lixo e folhas), acarretando diversos problemas operacionais em todas as etapas dos sistemas de coleta.

Neste cenário, é urgente a adoção de medidas que minimizem esta dinâmica de poluição. Algumas soluçóes estão sendo implementadas, contudo de forma ainda precária e não prioritária, sem a necessária avaliaçáo sistêmica de alternativas e resultados.

É esta temática que enfocada neste trabalho. Pretende-se analisar a problemática das interconexóes entre os sistemas de esgotamento sanitário, a drenagem pluvial e conseqüente poluição dos corpos hídricos da Cidade do Rio de Janeiro, verificando até que ponto o tipo de sistema oficialmente concebido - separador absoluto - de fato contempla suas funçôes sanitárias e ambientais de coleta, transporte e destino final adequado dos esgotos sanitários. Inicialmente apresenta-se a caracterizaçáo das coleçôes hídricas da Cidade do Rio de Janeiro, seguido da descrição dos sistemas 
de esgotamento, com especial destaque aos sistemas atípicos desses sistemas. Finalmente apresenta-se uma discussão sob o ponto de vista holístico do problema.

\section{CARACTERIZAÇÃO DAS COLEÇÓES HÍDRICAS NA CIDADE DO RIO DE JANEIRO}

A Cidade do Rio de Janeiro conta com um sistema hídrico, que inclui cerca de 250 rios e canais, complexos sistemas lagunares, dos quais fazem parte a lagoa Rodrigo de Freitas e as lagunas da baixada de Jacarepaguá. Em sua extensa costa litorânea $(86 \mathrm{~km})$, limitada a leste pela baía de Guanabara, a oeste pela baía de Sepetiba e ao sul pelo Oceano Atlântico, encontram-se 72 praias (PCRJ, 2001, v.9).

Os rios cariocas caracterizam-se por modesto volume d'água, sinuosidade dos cursos, ausência de direção dominante e dificuldades de escoamento devido aos percursos de extensas áreas planas e com baixas cotas. Essas características, associadas a um regime pluvial tropical, com chuvas intensas no verão, tornam os rios suscetíveis a transbordamentos, a enchentes periódicas e alagamentos permanentes em certas áreas, intensificados nos períodos de aumento dos níveis de maré. Em sua maioria, são canalizados, retificados e cobertos por ruas e avenidas (PCRJ, 2001, v.9). A figura 1 apresenta mapa hidrográfico da cidade.

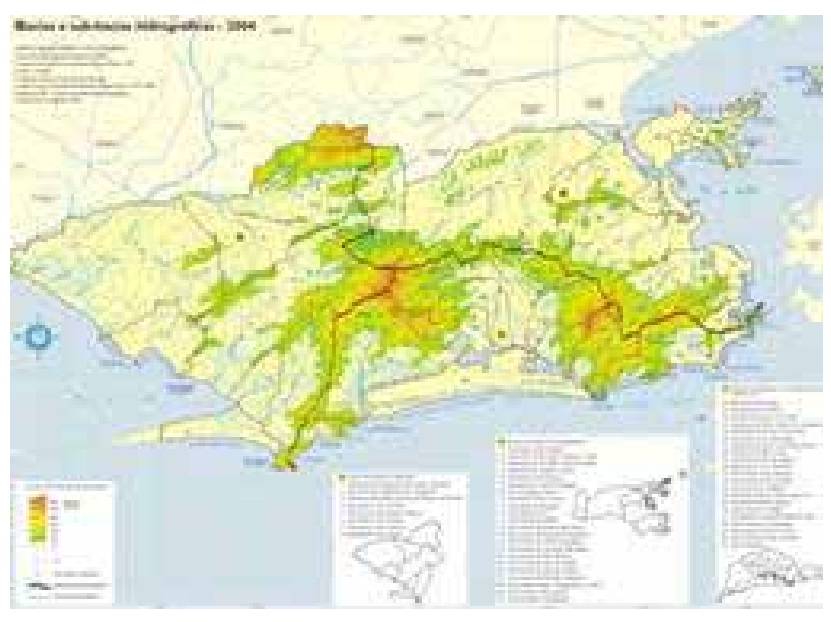

Figura 1. Mapa hidrográfico da Cidade do Rio de Janeiro, 2009.

Em termos de fontes de abastecimento de água, o Rio de Janeiro passou toda sua história realizando grandes esforços na luta pela água. Já afir- mava Coaracy (1965): "desde as suas origens foi sempre o Rio de Janeiro uma cidade com sede". Diversas obras foram implementadas na tentativa de resolver problemas distintos, relacionados aos componentes do sistema de abastecimento público, em todas as suas fases.

A população carioca aproveitou-se, no curso de sua história, de diversos mananciais locais, nos seguintes sistemas: a) Santa Tereza: Carioca, Lagoinha, Paineiras; b) Tijuca: Maracanã, São João, Trapicheiros, Andaraí, Cascatinha, Gávea Pequena; c) Gávea: Chácara da Bica, Piaçava, Cabeças, Macacos; d) Jacarepaguá: Três Rios, Rio Grande, Covanca, Camorim; e) Campo Grande: Mendanha, Cabuçu, Quininha, Batalha; f) Guaratiba: Taxas, Andorinhas, (Silva, 1988). Dentre eles, o rio Carioca, enquanto primeiro manancial superficial, desempenhou função estratégica para a cidade durante longo tempo, sendo um marco natural da cidade (Rosso e Dias, 2005).

Frente ao crescimento de demandas, associado ao avanço do processo de desmatamento, poluição e devido à sua pouca capacidade de abastecimento, gradualmente estas coleçóes hídricas deixaram de servir como mananciais. Ainda no governo imperial, em 1870, a soluçáo adotada foi a captação em mananciais cada vez mais distantes (Telles, 1984). Atualmente, a Regiáo Metropolitana do Rio de Janeiro é abastecida pelas águas originadas no rio Guandu, formado pela junção das águas dos rios Ribeirão das Lajes, Piraí e Paraíba do Sul. A Estação de Tratamento de Água do Guandu, de acordo com o registro no Guinees $B o o k$, é a maior estação de tratamento de água de produção contínua do mundo, com vazão de 43 $\mathrm{m}^{3} / \mathrm{s}$.

Por outro lado - os canais de esgoto - no sentido de conduto de esgotos sanitário e industrial - tem sido, por vezes, a denominaçáo comum adotada pela populaçáo do Rio de Janeiro, para designar a maioria dos rios, canais e córregos que atravessam sua cidade, e que, como tal, deveriam ser reconhecidos. Diante das evidências torna-se difícil para qualquer especialista desfazer tal confusão e discriminar as causas que culminaram no atual estado de degradação ambiental.

A alta densidade na urbanização gera inevitavelmente impactos ambientais sobre os recursos naturais, contudo os impactos nas bacias hidrográficas são mais resultantes do uso perdulário de seus recursos do que do aproveitamento 
das riquezas naturais nela disponíveis. A forma como se deu a metropolizaçáo da cidade - sem planejamento urbano e preocupação com os ecossistemas - potencializou os impactos ambientais negativos sobre as bacias hidrográficas, destacando-se: a) lançamento de esgotos sanitários e não domésticos; b) lançamento de fertilizantes e pesticidas provenientes de atividades agropecuárias; c) impermeabilização dos solos; d) vazadouro de resíduos sólidos, incluindo flutuantes; e) carreamento de sedimentos, nutrientes, húmus do solo, derivados de petróleo e resíduos sólidos para a calha dos rios; $f$ ) aterros, autorizados e clandestinos; g) subtração do leito e das áreas de várzea para incorporação às funçóes urbanas; $h$ ) descaracterização das condiçóes naturais, através de desvios e canalizaçóes do leito; i) ocupação desordenada das margens; $j$ ) desmatamento; $k$ ) assoreamento; l) extração de areia; $m$ ) poluição atmosférica; $n$ ) poluição resultante de acidentes ambientais, etc.

Em termos de coleta de esgotos e sistemas de drenagem, persiste na cidade do Rio de Janeiro, uma série de estruturas e condições de operação que indicam o alto grau de interconexão entre os sistemas de esgotamento sanitário e de drenagem pluvial, o que contribui com a degradação ambiental e a vulnerabilidade desses sistemas de saneamento. Uma descrição dessas estruturas e condições operacionais dessas interconexões é apresentada a seguir.

\section{ESTRUTURAS E CONDIÇÓES OPERACIONAIS DAS INTERCONEXÓES}

A interconexão entre os sistemas de esgoto sanitário e a drenagem pluvial ocorre de várias formas, desde a ligação das instalaçóes prediais de esgoto sanitário nas instalaçóes de águas pluviais internas dos imóveis e loteamentos até o lançamento final de trechos das galerias de águas pluviais na rede de esgoto sanitário.

Diversas circunstâncias podem ser classificadas como causa ou efeito destas interconexôes, inclusive alternando-se ciclicamente nesta relação, de forma cumulativa e sinérgica. As principais estão identificadas a seguir: a) regióes sem sistema público de esgotamento sanitário; $b$ ) reminiscências de sistemas antigos: separador parcial ou unitário; c) defasagem na implantação e ampliação das etapas dos componentes do sistema; $d$ ) prorrogação da utilização de componentes obsoletos do sistema; $e$ ) falta de prioridade aos serviços de operação, manutenção e conservação; $f$ ) modelo de urbanização e falta de planejamento urbano; $g$ ) dificuldades na fiscalização de obras; $h$ ) descontrole sobre as ligaçóes prediais irregulares; $i$ ) custos na implantação das ligaçôes prediais; $j$ ) instalações prediais inadequadas; $k$ ) tratamento ineficaz; $l$ aspectos culturais e educativos; $m$ ) adoção de estruturas atípicas do sistema separador absoluto.

No Rio de Janeiro, as interconexôes estão presentes desde a instalação dos seus sistemas iniciais de esgotamento. Os primeiros sistemas de esgotos no Rio de Janeiro foram os do tipo separador parcial, no qual se transportava além do esgoto sanitário, as águas pluviais que precipitavam sobre os lotes das residências. A partir de 1912, a orientação dada pelo governo era de que o novo sistema, separador absoluto, no qual o esgoto sanitário deveria ser totalmente segregado das águas pluviais, fosse aplicado nas novas intervençôes. Esta medida, de grande alcance técnico, resultou em uma ampliação indireta e gradativa da capacidade de vazão da rede construída, graças à eliminação metódica que se foi processando nas contribuiçóes pluviais dos prédios antes esgotados pelo sistema separador parcial e que vieram a sofrer obras de reconstrução (Silva, 2002). Isso implicou na utilização dessas tubulaçóes, que passaram a estar superdimensionadas, em sucessivas expansões ocorridas nestas bacias, daí a longevidade da utilização dessas tubulaçôes para o esgotamento sanitário. Entretanto, por acabarem sendo utilizadas para além da capacidade dos seus materiais constituintes, trechos antigos, inclusive com idades superiores a 100 (cem) anos, de tecnologia obsoleta, exigem nos dias de hoje, reparos constantes, com dificuldades operacionais acumulativas. Acrescido a este fato, algumas áreas que já dispunham do sistema misto, foram, em relação a outras que não dispunham de nenhum sistema, secundarizadas na implantação do novo tipo de esgotamento.

A possibilidade de desvio dos esgotos sanitários do tratamento, lançando diretamente na orla marítima, devido ao incremento das águas pluviais fazia parte da concepçáo do sistema misto, que preconizava atender a um determinado limite de vazão, proveniente dos esgotos sanitários, acrescido de determinada intensidade das águas de chuvas.

Segundo Britto (2002), o período do sistema misto assinala o início do uso oficial das 
galerias de águas pluviais como sistema auxiliar das redes de esgoto sanitário, através do extravasamento. Criava-se o conceito que prevaleceria até os dias de hoje, de água de tempo seco, que são os esgotos sanitários irregulares direcionados para as galerias de águas pluviais na ausência de precipitaçóes.

Posteriormente, as estruturas de captação de tempo seco foram sendo implantadas com o objetivo de tentar proteger alguns trechos de corpos hídricos do aporte de águas residuárias. No entanto, quando as chuvas superam a capacidade de escoamento ou ocorre paralisação por falha no sistema de bombeamento ou ainda, por mera falta de manutenção, o esgoto sanitário é desviado por by pass e lançado diretamente nas praias.

A prorrogação ou não ampliação dos sistemas existentes, seja no acréscimo da extensão da rede coletora ou na implantaçáo de outros componentes (estaçóes elevatórias e de tratamento, sifôes invertidos, etc.) trouxe graves dificuldades. Diante da constante escassez de recursos financeiros - ou pelo estabelecimento de outras prioridades - a solução mais utilizada nas grandes cidades brasileiras, inclusive no Rio de Janeiro, foi a construçáo de trechos de redes coletoras, para, pelo menos, afastar o esgoto sanitário das proximidades das residências, evitando-se assim o risco iminente de contaminação, transferindo o problema ao entorno e a jusante através dos cursos d'água. Estabeleceu-se, como última etapa, a construção das estações de tratamento. Esta precária solução trouxe a fragmentação das soluçóes projetadas, e desarticulou os componentes dos sistemas intensificando a poluição das coleçóes hídricas ou da drenagem afluente a elas.

Outro ponto a ser considerado é a alta densidade de urbanização até mesmo no subsolo que sofre várias interferências, inclusive de estruturas desativadas, acarretando indisponibilidade do espaço físico. Este aspecto é agravado por sucessivas intervençóes que ocorrem, muitas de forma arbritária, pelas empresas construtoras ou até mesmo pelos técnicos das concessionárias, comprometendo a integridade das tubulaçóes e das estruturas já assentadas. As dificuldades para a realização de uma efetiva fiscalização de obras, especialmente as subterrâneas, são inúmeras. A preocupação com a qualidade na execução das obras a garantir recursos necessários para a atuação de uma fiscalização compatível com o empreendimento vem cada vez mais se tornando uma exceção à regra no país.

O problema se agrava com o lançamento de grandes poluentes originados nas indústrias, shoppings, instalaçóes da economia informal etc. e a presença de ligaçóes prediais irregulares. No último caso, as ligaçôes prediais irregulares não podem ser explicadas somente pela falta de planejamento urbano, pela carência de recursos do poder público e pelas dificuldades técnicas resultantes deste ou de outros fatores gerencias. A sociedade é carente dos mínimos conhecimentos a respeito dos serviços de infra-estrutura urbana, das informações básicas necessárias para a utilização adequada de suas instalaçóes prediais e de seu papel fundamental na preservaçáo do sistema como um todo. Além disso, as ligaçóes prediais feitas à custa dos respectivos proprietários oneram a população, que encontra grandes dificuldades em dispor de recursos financeiros para essas despesas.

Finalmente observa-se que as atuais estaçōes de tratamento de esgoto sanitário sob gerência da Companhia de Água e Esgotos do Rio de Janeiro (CEDAE) ${ }^{3}$, também sofrem com as variaçôes das características qualitativas e quantitativas dos afluentes que ocorrem em função dessas interconexóes. $\mathrm{O}$ aumento da vazáo afluente causado pela contribuição de esgoto pluvial pode gerar vazóes superiores à vazão máxima da estação, que é obrigada a desviar o excedente dos efluentes através da estruturas de desvio. A mudança das características dos afluentes, por diluição ou incremento dos poluentes incorporados pelos despejos domésticos, pluviais e industriais, compromete a capacidade de tratamento e aumenta os custos operacionais pela contrapartida do aumento de insumos para o tratamento (energia, produtos químicos, etc.), e do tempo de detenção dos processos e operaçóes unitárias que constituem a planta de tratamento das estações. A eficiência do tratamento abaixo do estabelecido nos projetos é uma constante, motivada por uma série de fatores. As atuais es-

\footnotetext{
3 O sistema de esgotamento sanitário no RJ, ratificado pelos planos diretores de esgotos e pelo Programa de Despoluição da Baía de Guanabara (PDBG), adota o modelo concentrado de tratamento, que corresponde a poucas unidades depuradoras de grande porte em oposição à concepção de sistema de tratamento distribuído, que pressupóe número maior de unidades de tratamento, de pequeno porte. Nota dos Autores.
} 
tações de tratamento de pequeno porte, sob responsabilidade operacional da concessionária ou de particulares, são mais susceptíveis às variaçóes dos esgotos afluentes. Portanto, a impossibilidade de operacionalidade dentro de vazóes de projetos definidas por histogramas de vazóes, compromete sua eficiência e pode transformar estaçôes de tratamento em verdadeiras "caixas de passagem" acumuladoras de poluentes, que agravam o problema ambiental ao invés de minimizá-lo. No Rio de Janeiro, esta condição é evidente pelo grande número de unidades de tratamento de pequeno porte e de soluçóes individualizadas de tanques sépticos que sofrem de precariedades na construçáo e na operacionalidade, estando sua eficiência praticamente anulada pela ausência de limpeza regular, funcionando em não conformidade com prescrito na legislação, poluindo os corpos receptores.

Observa-se assim que no decorrer das várias intervençôes ao longo da história, a Cidade do Rio de Janeiro possui uma série de estruturas consideradas atípicas do sistema separador absoluto descritas brevemente a seguir.

\section{ELEMENTOS ATÍPICOS DO SISTEMA SEPARADOR ABSOLUTO}

Devido às dificuldades geradas pela interconexão, diversas estruturas e condiçóes de operacionalidade foram gradualmente implantadas no sistema de esgotamento da Cidade do Rio de Janeiro, de forma precária ou mesmo projetadas, no intuito de amenizar os impactos causados pelo déficit na ampliação ou operaçáo inadequada dos sistemas existentes. Dentre eles destacam-se: a) Interceptor Oceânico da Zona Sul; b) galerias de cintura; $c$ ) captaçóes de tempo seco; d) aterros e desvios de rios e canais; $e$ ) extravasores permanentes; $f$ ) estaçóes de tratamento nos cursos em canais, rios e praias. Uma breve descrição de cada uma dessas estruturas é apresentada a seguir.

\section{INTERCEPTOR OCEÂNICO DA ZONA SUL}

Os interceptores de esgoto sanitário são canalizaçôes cuja função precípua é receber e transportar o esgoto sanitário coletado, caracterizado pela defasagem das contribuiçóes, da qual resulta o amortecimento das vazóes máximas (ABNT/ NBR 12.207/89). Este método de cálculo pos- sibilita o "achatamento" do hidrograma de vazão decorrente da defasagem horária das contribuiçôes em marcha, garantindo maior fidelidade e economia no dimensionamento do sistema.

No Rio de Janeiro foram previstos três interceptores: Interceptor Oceânico da Zona Sul; Interceptor Norte, abrangendo bacias tributárias situadas nas vertentes da baía de Sepetiba; e o Interceptor Centro, para as áreas tributárias de parte do Centro e da Zona Portuária. Os esgotos transportados por esses interceptores seriam encaminhados ao Emissário Submarino de Ipanema (ESEI). Posteriormente, concluiu-se que, do ponto de vista técnico e financeiro, a melhor alternativa seria o lançamento dos esgotos da Zona Norte e do Centro seria na baía de Guanabara, com tratamento prévio. Esta opçáo foi ratificada e implantada pelo Programa de Despoluiçáo da Baía de Guanabara (DIAS, 2003). As obras do Interceptor Oceânico da Zona Sul iniciaram-se em 1962 e foram concluídas em 1972, entrando em operação em 1975. Seu traçado utilizou-se dos aterros realizados no Flamengo e do alargamento da praia de Copacabana, construído inteiramente em concreto armado, com seçóes progressivamente variadas, conforme observado nas figuras $2 \mathrm{a}$, $2 \mathrm{~b}$ e 3 .
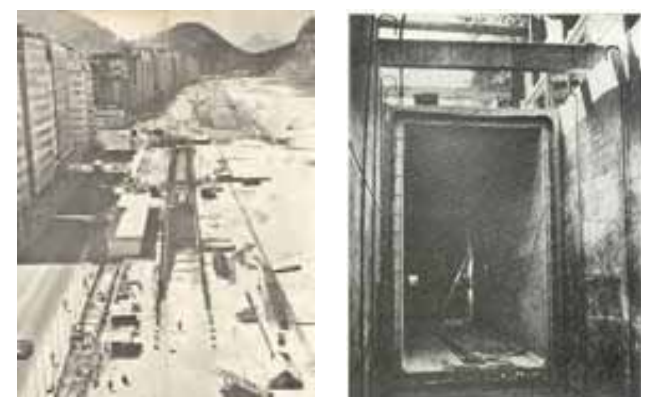

Figuras 2. a) Alargamento da praia de Copacabana e assentamento do interceptor; $b$ ) Seção retangular no trecho da Av. Osvaldo Cruz; (Fonte: a) Revista Saneamento no. 38, 1970. b) Revista de Engenharia no. 1, 1965.

$\mathrm{Na}$ concepção e construção do Interceptor Oceânico da Zona Sul planejou-se, além da condução de esgoto sanitário, a coleta e o transporte das águas poluídas provenientes do sistema de drenagem pluvial, denominadas contribuiçáo de tempo seco (ABNT/NBR 12.207/89) e a dos esgotos provenientes das ligaçóes prediais da orla marítima, desde a Glória até Copacabana, visando eliminar a poluição nas praias pelo aporte indevi- 
do de esgoto sanitário (Silva, 2002), o que de fato não se efetivou.

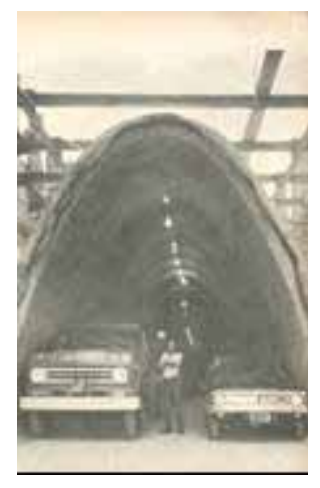

Figura 3. Seção em arco no trecho de Copacabana. (Fonte: Revista Saneamento n ${ }^{\circ} .38$, 1970).

\section{GALERIAS DE CINTURA}

Galerias de cintura são canalizações abertas ou fechadas, além de tubulações, que interceptam os pontos de lançamento de galerias de águas pluviais contaminadas ou diretamente de ligaçóes irregulares de esgoto sanitário e concentram suas vazóes para lançamento em pontos previamente fixados. Em alguns casos, os despejos dos efluentes são apenas redirecionados precariamente para outros pontos, menos valorizados ou discretos. Em outras situaçóes estas galerias possuem efluentes captados e encaminhados para o sistema de esgotamento sanitário, como o ESEI.

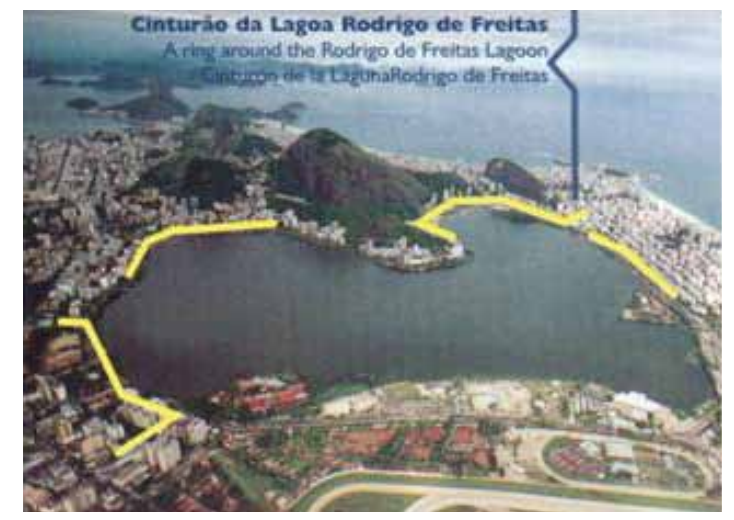

Figura 4. Galeria de cintura da lagoa Rodrigo de Freitas. (Prospecto CEDAE, 2003).

As galerias de cintura foram implantadas em diversos trechos da orla marítima, tais como: praias do Flamengo, Leblon, Copacabana, Botafogo, recentemente a galeria da praia de Ipanema (entre a Teixeira de Melo e o Jardim de Ala), a galeria de cintura da lagoa Rodrigo de Freitas, além de outras, em fases de projetos e implantação, como a galeria de cintura da Estrada das Canoas e da Niemeyer, ambas dentro do Programa de Despoluição da Praia de São Conrado. A figura 4 apresenta como exemplo o traçado da galeria de cintura da lagoa Rodrigo de Freitas, que não impediu a continuidade de lançamento de ligaçóes clandestina na laguna.

\section{CAPTAÇÓEES DE TEMPO SECO (CTS)}

As estruturas denominadas captaçáo de tempo seco estáo inseridas nas galerias de águas pluviais capazes de desviar a vazão remanescente que é encontrada quando do estio. Tais vazóes são geralmente provenientes de ligaçóes indevidas de esgoto sanitário na rede de drenagem pluvial. Enquanto contribuição de tempo seco (conhecida também por "água de tempo seco") direciona, nos períodos sem chuva, os esgotos clandestinos contidos no sistema de drenagem para o sistema de esgotamento sanitário. No período chuvoso extravasa as águas poluídas (águas pluviais e esgoto sanitário) para o sistema de drenagem pluvial (ABNT/NBR 12.207). Essas caixas de transição têm sua capacidade de transmissão de vazão limitada por aspectos construtivos, de forma que apenas vazóes iguais ou inferiores à sua capacidade máxima, definida conforme suas dimensóes e nível da soleira podem ser encaminhadas ao sistema de esgotamento sanitário. Somente na bacia contribuinte da lagoa Rodrigo de Freitas é possível observar a presença de seis unidades de captação de tempo seco, totalizando uma vazão de $226 \mathrm{~L} / \mathrm{s}$, segundo o Plano Diretor de Esgotamento Sanitário da Regiáo Metropolitana do Rio de Janeiro e das Bacias Contribuintes à Baía de Guanabara de 1994 (CEDAE, 1994). Maiores detalhes quanto a essas estruturas podem ser observados em Rosso e D'Alcantara (2006).

\section{ATERROS E DESVIOS DE RIOS E CANAIS}

Os aterros e desvios de rios e canais poluídos, na tentativa de salvaguardar determinado corpo receptor em detrimento de outros, ou mesmo para afastar a possibilidade de contato e diminuir a visibilidade da poluição, é uma prática comum e antiga nos grandes centros urbanos. No Rio de Janeiro, vários cursos d'água nesta situação foram aterrados e, quando náo possível, canalizados em galerias subterrâneas. 
Um bem exemplo dessa prática foram as obras realizadas por volta de 1920. Inspiradas nos conceitos de Barão de Tefé, Saturnino de Brito (1943) interceptou os rios Cabeças, dos Macacos e Rainha, que contribuíam permanentemente com suas águas para a lagoa Rodrigo de Freitas. Desta Forma, as águas dos rios Cabeças, Macacos e Rainha foram conduzidas para o canal da avenida Visconde de Albuquerque, desembocando a seguir na praia do Leblon.

O impacto ambiental sobre as praias do Leblon e Ipanema provocada pelo aporte de esgoto sanitário proveniente do canal da avenida Visconde Albuquerque, criou um impasse que fez o Governo do Estado implantar uma nova comporta neste canal, com a instalação de bombas para transportar as águas contaminadas para o ESEI, na tentativa de minimizar os efeitos da contaminação das praias e da lagoa Rodrigo de Freitas. Como o recalque é de uma parcela das águas poluídas, ocorre retenção de esgoto sanitário a céu aberto nos canais, com interrupção das condições originais de escoamento. Nos períodos de chuva as comportas são abertas para impedir inundaçóes e as águas pluviais contaminadas são desaguadas na praia e na lagoa Rodrigo de Freitas. A figura 5 representa esquematicamente o percurso dos rios anteriormente citados, o posicionamento das comportas, o sistema de recalque das águas poluídas do canal e a possibilidade de refluxo para a lagoa Rodrigo de Freitas.

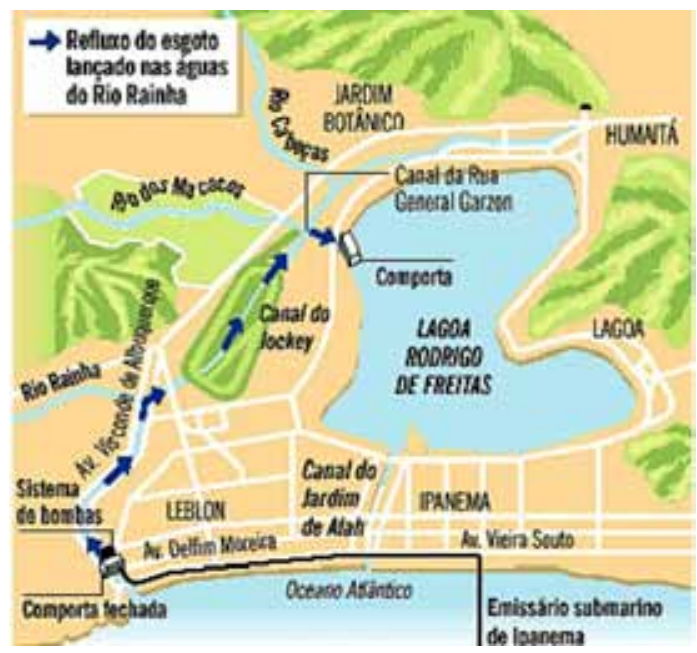

Figura 5. Esquema das estruturas de esgotamento da lagoa Rodrigo de Freitas. (Jornal O Globo, 2002).

Alternativa de desvio de rios está novamente sendo cogitada visando minimizar os problemas de abastecimento de água da Região Metropolitana do Rio de Janeiro (RMRJ), especificamente da poluição do rio Guandu, próximo ao ponto de captação da Estação de Tratamento de Água da CEDAE. O aporte próximo da tomada d'água das águas poluídas provenientes dos rios dos Poços, Queimados e Ipiranga vem comprometendo a tratabilidade da água do manancial, trazendo riscos iminentes à população beneficiada, além do comprometimento de outros usos a jusante deste ponto. Uma das alternativas apontada propóe o desvio das águas desses rios afluentes ao rio Guandu, para imediatamente a jusante da tomada d'água, associado recentemente ao incremento de um tratamento prévio das águas, na própria calha dos afluentes citados (Gomes et al., 2002).

\section{EXTRAVASORES PERMANENTES}

Os extravasores de esgoto sanitário, segundo o decreto estadual $n^{\circ} 533 / 76$, devem ser concebidos nos projetos de sistemas de esgotos para escoar eventuais excessos de esgoto ou de água. Estas canalizações ou estruturas são projetadas nas tubulaçōes, canais, órgãos acessórios, elevatórias e nas Estaçóes de Tratamento de Esgotos(ETE's), uma vez que o escoamento dos sistemas por gravidade é contínuo e eventualmente necessitam desviar o fluxo, por questóes de manutenção, manobras ou para desviar excedentes de água para controle de inundaçóes, no caso do sistema de drenagem pluvial.

Localizados em cotas superiores ao nível de escoamento normal, entram automaticamente em operaçáo quando o efluente chega no nível da tubulação de extravasão fazendo o lançamento do esgoto sanitário, através de estruturas especiais, no sistema de drenagem, nos cursos d'água e corpos receptores. Com isso é possível eliminar a causa da interrupção do sistema, de forma que não haja um colapso com fluxo indevido de esgoto para as vias públicas ou para os domicílios, através do retorno, em sentido contrário ao escoamento, pelas tubulaçóes da rede pública e pelas ligaçóes prediais, condição de operação denominado remanso.

A utilização dos extravasores para além dos casos especiais previstos, eventuais e de curta duração, configura atipicidade de procedimento e de elementos. Por uma questão de distinção daqueles convencionalmente projetados e operacionalizados, optou-se por chamar a estes, que freqüentemente entram em operação, de "extravasores 
permanentes". Este extravasamento ocorre desde a implantação das primeiras redes, e, atualmente está presente em diversas estruturas que compóem o sistema de coleta, transporte e tratamento de esgoto sanitário da cidade do Rio de Janeiro.

As sobrecargas e dificuldade de escoamento em diversos trechos do sistema obrigam empresas, construtoras, moradores e a própria concessionária a realizar interconexóes com a drenagem pluvial, utilizando-se desta como um "sistema auxiliar", a fim de impedir os transbordamentos de esgoto sanitário pela via pública.

Os pontos de extravasamento "permanentes" estáo espacialmente disseminados por todo o sistema. Segundo Britto (2002), a prática de extravasores não era oficial, e os responsáveis que a praticavam dificilmente cadastravam a ligação realizada.

\section{ESTAÇÓES DE TRATAMENTO NOS CURSOS DOS CANAIS, RIOS E PRAIAS}

Em vários estados do país, como: São Paulo, Paraná, Santa Catarina, Minas Gerais e mais recentemente, o Rio de Janeiro, vêm sendo introduzidas unidades de tratamento nos cursos d'água, tecnologia denominada estaçóes de tratamento em fluxo, que objetivam melhorar a qualidade dos recursos hídricos poluídos, diferentemente das finalidades de produção de água potável (ETA) e tratamento de água residuárias para lançamento adequado nos corpos receptores (ETE). No Rio de Janeiro, quatro situaçóes podem ser observadas conforme apresentadas a seguir.

\section{ESTAÇÃO DE DESPOLUIÇÃO DO RIO CARIOCA}

No caso do tratamento em fluxo do rio Carioca, utilizam-se processos físico-químicos de floculação seguido de flotação. Para isso são adicionados os insumos: reagentes coagulantes/ floculantes, cloro, ar dissolvido e energia elétrica, ajustados para diferentes vazóes de acordo com os objetivos ambientais. A Estação de Despoluição do rio Carioca está instalada próxima a sua desembocadura na beira da praia, no canal da galeria de cintura, construído anteriormente para desvio da foz do rio e da intercepção das galerias de águas pluviais, também contaminados por esgoto sanitário. O lodo flotado é direcionado à rede coletora de esgoto sanitário, sendo encaminhado para o ESEI.

O princípio básico desta tecnologia consiste no tratamento das águas na iminência de seu lançamento na praia, o que limita seu objetivo em não poluir a praia do Flamengo pelos esgotos transportados pelo rio Carioca e pelas galerias de águas pluviais que são interceptadas pelo canal da galeria de cintura, visando trazer nas imediaçóes da desembocadura as condiçóes de balneabilidade. Desta forma, esta concepção pode ser considerada como uma solução pontual.

A estação funciona somente nos períodos de seca, com vazão máxima de projeto de $300 \mathrm{~L} / \mathrm{s}$. Em caso de chuvas o processo é interrompido, liberando a passagem do fluxo de águas contaminadas para a praia do Flamengo. As figuras 6, 7 e 8 apresentam detalhes da Estaçáo de Tratamento do rio Carioca.

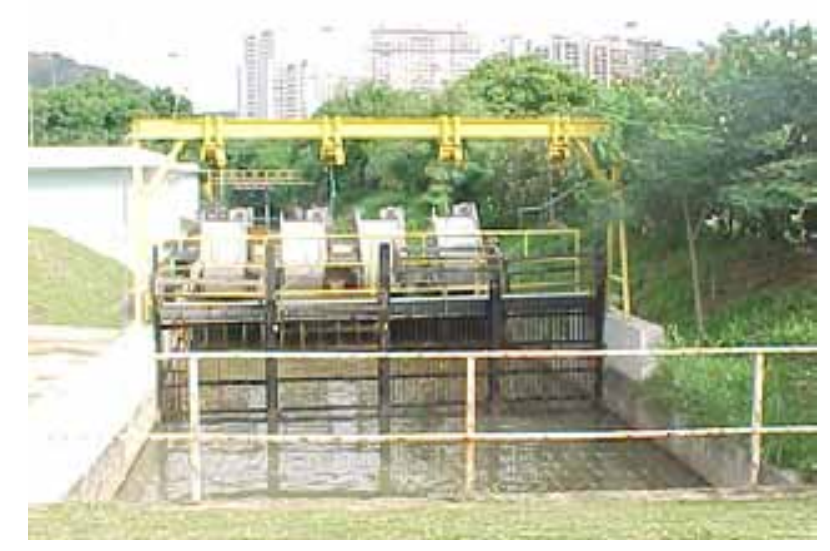

Figura 6. Estação de tratamento do rio Carioca: Estrutura de gradeamento (Fotos: DIAS, A.P.15/04/03).

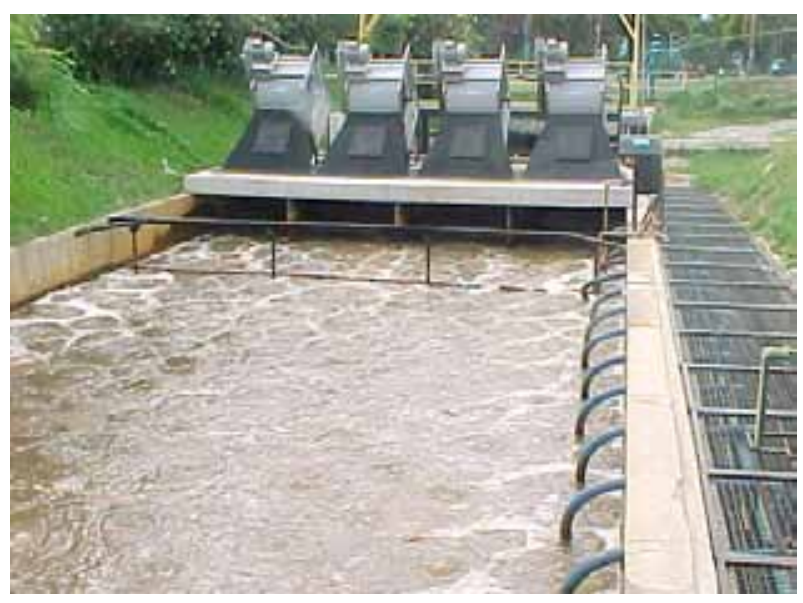

Figura 5. Estação de tratamento do rio Carioca: Microaeração da massa líquida (Fotos: DIAS, A.P.15/04/03). 


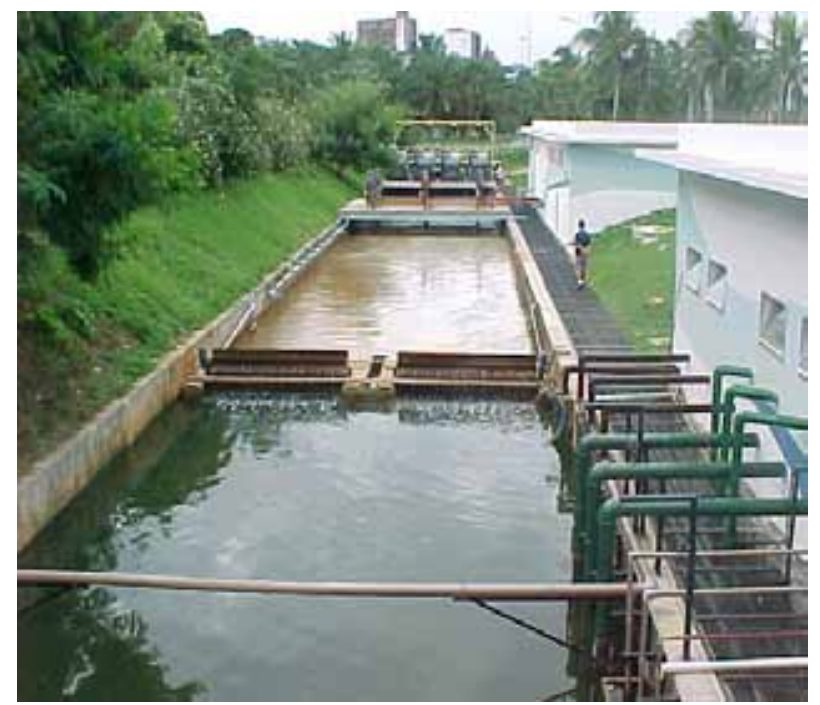

Figura 5. Estação de tratamento do rio Carioca: Remoção de lodo flotado (Fotos: DIAS,

A.P.15/04/03).

\section{ESTAÇÃO DE DESPOLUIÇÃO DO CANAL DA ROCINHA}

Outra unidade de flotação em fluxo em fase de implantação é a Estação de Despoluição do Canal da Rocinha, localizada na Favela da Rocinha (Lagoinha), com capacidade de $300 \mathrm{~L} / \mathrm{s}$ (com possibilidade de ampliação para $900 \mathrm{~L} / \mathrm{s}$ ). Esta contribuiçáo corresponde ao esgoto proveniente da sub-bacia de São Conrado, que engloba os bairros de São Conrado, vertente São Conrado da favela da Rocinha e morro do Vidigal.

Este empreendimento em execuçáo faz parte das obras de despoluição da praia de São Conrado contemplando a construção de galerias de cintura ao longo da praia para captar águas pluviais contaminadas, estaçôes automáticas de remoção de lixo e implantação de extravasor.

\section{PARQUE AMBIENTAL DA PRAIA DE RAMOS}

A concepção adotada no Parque Aquático de Ramos, popularmente conhecido "Piscinão de Ramos”, em operação desde 2001, difere da praia do Flamengo por tratar as águas da baía de Guanabara já contaminadas pelo grande aporte de águas residuárias. Optou-se neste caso pelo tratamento da parcela de água do mar utilizada no enchimento da piscina artificial, com $26.000 \mathrm{~m}^{2}$ de espelho d'água, instalada nas areias da praia. Quanto ao processo de tratamento, é similar ao da Estação de Despoluição do rio Carioca. As águas próximas à praia de Ramos recebem esgoto sanitário proveniente principalmente de dois valóes que ali desembocam. Com a implantação da estação, $100 \mathrm{~L} / \mathrm{s}$ de águas salinas contaminadas sofrem remoção dos resíduos sólidos e posterior tratamento, viabilizando-se a recreaçáo, outrora feita diretamente na praia, antes das condiçóes precárias de poluição.

A carga orgânica removida no tratamento é encaminhada através de uma derivaçáo da CEDAE para a Estação de Tratamento de Esgoto da Penha.

Outra situação semelhante é o Piscinão de São Gonçalo, também localizado na baía de Guanabara, que desde sua inauguração, vem apresentando diversos problemas de operação e manutenção, sendo paralisado em diversas ocasióes. Existe a previsão para a implantação de outros "piscinões" em Magé, Duque de Caxias, Nova Sepetiba e praia de Cocotá, na Ilha do Governador (Revista Bio, 2002).

\section{DISCUSSÃO}

A primeira e mais evidente forma de aporte de esgoto sanitário no sistema de drenagem pluvial está nas áreas que ainda não dispóem de sistema público de coleta e transporte deste efluente. Mesmo com o alto índice de atendimento de coleta de esgoto na cidade as coleçóes hídricas que passam por áreas desprovidas destes serviços ficam comprometidas, principalmente quando as bacias apresentam alta densidade populacional ou intensa atividade industrial. A solução individual de construção de tanques sépticos precedente ao lançamento final dos esgotos no sistema de drenagem mostra-se precária pelo baixo grau de eficiência do tratamento e, principalmente, pela inadequada construção e manutenção das unidades, de responsabilidade e custeio privados. Este problema ocorre também nas estaçóes de tratamento de esgoto compactas, de responsabilidade de condomínios e conjuntos habitacionais.

O fato de os coletores de drenagem pluvial receberem aportes de esgoto sanitário devido as interconexóes, em áreas contempladas pelo sistema separador absoluto, não o torna um sistema unitário, uma vez que o tipo de efluente define diversas características das unidades que compóe os respectivos sistemas. Cada concepção deve ser previamente estabelecida e dimensionada para 
suas próprias condiçóes operacionais. Os esgotos sanitários, diferentemente das águas pluviais, não podem ser transportados em canais (seção aberta), mas em condutos subterrâneos que garantam a estanqueidade necessária. Outrossim, estes efluentes não podem ser lançados nos corpos receptores sem tratamento prévio, o que é permitido às águas lançadas pelas galerias de águas pluviais.

Portanto, o transporte de esgoto sanitário pelo sistema de drenagem pluvial e o aporte de águas pluviais no sistema de esgotamento sanitário são situações atípicas ao sistema separador absoluto. Para serem implementadas deveriam ser submetidas à rigorosa análise de alternativas, devidamente justificadas e subsidiadas por estudos de impacto ambiental, que considere os riscos sanitários e ambientais.

Em sistemas unitários adequadamente concebidos e projetados, dispositivos de regulagem e manobras, bem como vertedores e tanques de acumulação, reduzem apreciavelmente a poluição dos corpos receptores. Após a ocorrência de chuvas, a água armazenada pode ser bombeada para estaçôes de tratamento. A aplicação de extravasores em um sistema de esgotamento do tipo unitário ou misto requer estudos de hidrogramas de contribuiçóes a fim de se conhecer a freqüência, as vazóes e os volumes de extravasamento, mantendo-se assim as condiçóes de qualidade desejadas para os corpos receptores. Este esgotamento é concebido para tratar um determinado limite de vazão, superior à vazão de tempo seco, podendo inclusive, contemplar tanques de acumulação capazes de reter determinado volume de água pluvial correspondente a um tempo de recorrência fixado. Desta forma, o projeto sofre uma análise de custo-benefício, onde a análise de riscos sanitários e ambientais devem estar inseridos, sendo os extravasores, parte da operacionalizaçáo do sistema. Situaçáo completamente distinta da que vem acontecendo desde longa data, na cidade do Rio de Janeiro.

O próprio Interceptor Oceânico da Zona Sul, projetado para receber, além das contribuiçóes do sistema de esgotamento sanitário, os esgotos que afluíam das galerias de drenagem contribuintes à orla marítima - subsistema concebido como unitário - passaram a ter, por acúmulo de problemas operacionais, a disfunção de extravasar os esgotos coletados, promovendo a poluição das praias em determinadas condições de chuvas.
Estas improvisaçôes emergenciais quase nunca são desfeitas, deixando o sistema sujeito a mau funcionamento hidráulico, sem autolimpeza, com incremento de material sedimentável, distanciando-se da original organização de esgotamento das bacias. Esta desfiguração é um empecilho a estudos, projetos e análises de desempenho. Em muitos casos, não há registros destas obras, nem identificação dos extravasamentos e rompimentos na rede.

Quanto às interconexóes dos sistemas de esgotos provenientes de inadequadas instalações prediais e ligaçóes prediais nos coletores públicos, vale ressaltar sua relevância através das palavras, ainda atuais, de Brito (Obras, v.II, 1909):

\section{não raro deverão atribuir ao mau funciona- mento do esgoto - o intestino da casa - cer- tos males que em vão procurem combater nos moradores doentes, será então preciso sanear a casa para curar o doente.}

Mesmo com a permuta de poder, os diversos governos de estado identificam os extravasores e as ligaçóes prediais irregulares como um problema que deve ser solucionado. Entretanto, até o momento não foi implantado nenhum programa contínuo em larga escala, que priorizasse esta finalidade e possibilitasse recuperar a configuraçáo original dos sistemas, orientando-se por estudos, projetos e cadastros técnicos.

As soluções atípicas ao sistema separador absoluto, decorrentes das interconexões arbitrárias, sem projetos formais de alteraçáo, improvisadas, ou mesmo as concebidas e fundamentadas em projetos, são implementadas com a precária justificativa da viabilidade emergencial ou provisória, mas muitas vezes acabam por funcionar definitivamente, com reflexos sobre a eficiência dos sistemas de saneamento e sua credibilidade.

Parece redundante a afirmação de que os sistemas devem operar conforme concebidos em projetos. Não obstante, observa-se ser este um dos maiores problemas dos sistemas de esgotos do município do Rio de Janeiro. As práticas precárias e informais de operacionalização da rede coletora de esgoto sanitário são, em muitos casos, executadas sem a mínima condição técnica, limitando-se a impedir o transbordamento de esgotos nas vias públicas. Com isso, não são avaliados os impactos dos sistemas envolvidos no meio ambiente. A falta de cadastro do sistema e de suas alteraçóes torna- 
-o vulnerável, como se constata na avaliação da auditoria ambiental da lagoa Rodrigo de Freitas (LA ROVERE et al., 2001), que pode, inclusive, ser estendida para outras áreas da cidade.

\section{(...) Com efeito a indisponibilidade nos locais} de trabalho de documentos técnicos de engenharia (por exemplo, plantas de situação e cortes \& elevaçôes, folhas de dados de equipamentos e fluxogramas de engenharia, entre outros), a deficiência da comunicação entre $o$ cadastro e as unidades operacionais (o que determina a não revisão \& atualização dos desenhos das instalaçôes para manutenção), a inexistência de procedimentos operacionais escritos e documentados e consolidados em um Manual de Operaçóes (tanto os relacionados com a operação do sistema em regime normal, quanto os relacionados com situaçôes $e$ eventos de emergência), a inexistência de um programa de inspeção e manutenção preventiva dos elementos do sistema (a manutenção é corretiva, sendo, a maioria das vezes, iniciada por situaçóes de anormalidade operacional; em uma palavra: "manutenção tipo apagar incêndio") e a constatação da não realização de treinamento do operadores, caracteriza um quadro de improvisação gerencial.

Nas captaçôes de tempo seco, também atípicas, para sua aplicação adequada, deve-se verificar o excedente de vazão, conhecer a freqüência dos extravasamentos, as vazóes e os respectivos volumes dos esgotos eliminados nos corpos hídricos (Goldenfum et al., 1997). Ao que tudo indica este estudo não é realizado no Rio de Janeiro e conseqüentemente, náo são avaliados os impactos no sistema de drenagem pluvial e nos corpos receptores. Este recurso também é feito, de forma precária, diretamente nas galerias de drenagem, através da implantação de soleiras vertentes nos próprios condutos.

A aplicação da idéia de coletar e tratar apenas as vazóes de "tempo seco" do sistema pluvial conectado ao esgotamento sanitário conduzirá certamente a um sistema náo confiável. Por ocasião das cheias, o esgoto sanitário misturado às águas pluviais sem tratamento continuará a ter como destino final o solo, as coleçôes hídricas continentais e a orla marítima, aumentando o risco epidemiológico das inundações.
As galerias de cintura ao longo da orla marítima da Zona Sul foram utilizadas para transferir os poluentes para outros pontos menos valorizados ou visíveis em um dado momento, mantendo-se o problema. Algumas foram conectadas ao emissário e outras, posteriormente adequadas a esta situação.

A questão ficou reduzida à destinação final mais adequada das águas residuárias. Esta alternativa mantém as águas transportadas pelas galerias de águas pluviais poluídas pelo aporte irregular de esgoto sanitário. Os pontos de deságüe das galerias de drenagem distribuem-se naturalmente por toda a orla marítima e a implantação de galerias de cintura para impedir a poluição das praias pelas línguas negras se torna infactível, náo garantindo a segurança do sistema diante de chuvas intensas.

Com esta superposição de barreiras sanitárias, não se considera a necessidade de melhorias no sistema de esgotamento sanitário, concebido exatamente para impedir a poluição das praias, dos sistemas de drenagem pluvial e do solo. Atualmente as línguas negras se espalham por vários pontos da orla marítima, inclusive nos trechos contemplados por estas galerias de cintura, que inclusive se encontram depreciadas.

A opção pelos Aterros e Desvios de Rios e Canais incorre no mesmo erro de transferência de poluição, solução que no passado podia ter alguma justificativa, atualmente se torna obsoleta e inadequada, frente à limitaçáo dos recursos naturais, à condição de saturação da cidade e seu entorno e à consciência ambiental.

Para o rio Guandu, a proposta de transferência do deságüe dos rios dos Poços, Queimados e Ipiranga, de montante para jusante do ponto de tomada d'água, mesmo com a proposta de tratamento pontual no final curso do rio, significa incorrer em erro, pois náo recupera a condição ambiental ao longo da bacia hidrográfica, a qual não dispóe de redes de esgotamento sanitário. Com a possível implantação de nova estação de tratamento no rio associada ao desvio reitera-se a superposição de barreiras sanitárias. Por outro lado, iniciativas como o plantio de mudas para a recuperação da mata ciliar do rio Guandu e a inauguração do Centro de Produção de Mudas da Mata Atlântica Manuel Gomes Archer pela CEDAE se apresenta como importantes intervençóes de saneamento ambiental. 
No caso da lagoa Rodrigo de Freitas, se a galeria de cintura não trouxe resultados significativos ao balanço energético do sistema lacustre, as recentes intervençóes do sistema de esgotamento local, a exemplo da recuperação das elevatórias de esgotos, indicam a possibilidade de haver melhorias, não obstante, permanece o impasse, a partir do momento que não se opte também pela despoluição dos rios afluentes aos canais e do monitoramento destes.

Mesmo nos países com excelentes meios de controle técnico de equipamentos públicos, as duas redes de esgotos jamais atingem uma total separação. A diferença está no nível desta interconexão e na respectiva vulnerabilidade e comprometimento do sistema que, em nosso caso, vem tornando-se incapaz de atender às premissas ambientais, o que é exemplificado pelo estado de degradação das coleçôes hídricas.

Deve-se procurar equilibrar o grau de eficiência ou nível de segurança sanitária e ambiental requerida à disponibilidade de recursos para implantação, operação e manutenção. Não obstante, estes recursos devem ser suficientes para que a capacidade de proteçáo dos sistemas seja efetiva e não resulte em desperdício de investimentos em sistemas obsoletos, podendo eliminar as vantagens que o sistema separador absoluto possui frente aos outros tipos de esgotamento.

A desatenção com as causas da poluição dos corpos hídricos vem trazendo aumento do nível e expansão desta, o que resulta no acréscimo dos níveis de tratamento de água, com a implantação de tecnologias cada vez mais sofisticadas e superposição de tratamentos com a implantação de barreiras múltiplas de estaçóes ao longo do curso das águas, requerendo insumos de produtos e energia cada vez mais vultosos. Nesse contexto, o processo denominado "filtração rápida", antes considerado o ápice em termos de tratamento de água, está hoje em dia comprometido (Kligerman, 2001).

Até mesmo o principal manancial que abastece a cidade do Rio de Janeiro vem sofrendo com a poluição por esgotos sanitários e industriais. Os problemas ocorridos no verão de 2002 tiveram como principal destaque as algas azuis - cianobactérias - que proliferam em ambientes aquáticos poluídos por esgotos.
Segundo a CEDAE, em artigo publicado na Revista da FAPERJ (2002), há cerca de seis anos é adicionado ao tratamento, junto ao sulfato de alumínio, sais de ferro e polímeros, e estão em estudo novos produtos químicos para otimizar e intensificar o tratamento. Há dez anos os filtros funcionavam 24 horas seguidas. Hoje a operação de limpeza, pode ser readequada para 18 ou 12 horas.

Atualmente, a tecnologia de tratamento de água vem necessitando de técnicas adicionais aos processos denominados "convencionais" eles: a oxidação química, adsorção em carvão ativado e filtração em membranas de alta pressão, que foram evoluindo e sendo adicionadas ao processo, em decorrência do aumento do nível e variedade de poluentes. Isto gera a necessidade de mudança nos limites de parâmetros e a incorporação de outros, decorrentes de novos contaminantes, inclusive por suas açóes sinérgicas.

Vale ressaltar que todas estas alteraçôes partem do pressuposto de que haja uma administração eficiente das estaçóes de tratamento, com recursos suficientes e contínuos para atender as novas demandas operacionais. $\mathrm{O}$ aumento da eficiência dos tratamentos gera acréscimo nos rejeitos líquidos e sólidos que saem das estaçôes. O lodo gerado necessita de soluçôes e disposição final adequada e definitiva para náo impactar o meio ambiente.

Os problemas no tratamento dos esgotos sanitários começam antes da chegada nas estaçóes. Com a fragilidade dos sistemas de coleta e transporte, estas estaçóes ficam com suas rotinas operacionais e gerenciais comprometidas. A concepção adotada no Rio de Janeiro possui como característica a concentração das águas residuárias em unidades de tratamento de grande porte. Entretanto, o não atendimento à eficiência concebida pode resultar no agravamento das condiçóes ambientais. As ETEs devem estar submetidas, portanto, a um controle operacional rigoroso e sistemático.

A proposta da Estação de Despoluição do rio Carioca e de outras novas estaçóes em cursos d'água no Rio de Janeiro minimiza o problema da poluiçáo hídrica, como no deságüe na praia do Flamengo, mas não deixa de ser paliativa. Sua eficácia ainda há de ser comprovada no caso de ser

\footnotetext{
4 As estações de tratamento de água, do tipo convencionais, são constituídas pelos processos: coagulação, floculação, decantação, filtração e desinfecção.
} 
feito algum monitoramento ambiental, tanto nos aspectos epidemiológicos como mesológicos.

Não se pode concordar que uma intervenção atípica seja ambientalmente satisfatória. Sua própria concepção encerra caráter emergencial e um contra-senso, provocado pelo acúmulo histórico dos problemas de defasagem e manutençáo dos sistemas de esgotamento. $\mathrm{O}$ tratamento somente no desemboque propóe-se a garantir a balneabilidade da praia, próximo ao deságüe, mas não devolve à populaçáo local o curso do rio, que permanece poluído. Outro ponto a se considerar é a interligação com as águas da baía de Guanabara, cuja hidrodinâmica é condicionada aos movimentos das marés astronômicas e outras variáveis ambientais peculiares das áreas costeiras que podem trazer problemas no regime de operação e tratamento em uma estação tão próxima ao deságüe.

Atuando na conseqüência da falta de coleta e transporte dos esgotos sanitários gerados, a Estação de Despoluiçáo do Canal da Rocinha não impede a proximidade dos resíduos com a população, pois nas áreas peridomicilares não há melhoria nas condições sanitárias. Ainda hoje a estação apresenta problemas operacionais. Alternativas tecnológicas que não levam em consideração os usuários dos equipamentos desvinculam-se de qualquer processo de mudança e controle social.

A Estaçáo de Tratamento de Praias e o Piscinão de São Gonçalo coincidem com a alternativa anterior em não eliminar as fontes de poluição do corpo receptor, neste caso as praias. Prioriza o tratamento das águas já poluídas para o uso em atividades recreativas de balneabilidade, que por sua vez apresenta alto custo e problemas operacionais e de manutenção. Novamente, outras ações integradas relativas à melhoria efetiva do ecossistema marinho foram secundarizadas. A implantação de uma piscina artificial não devolveu ao carioca, e suprimiu ao ecossistema, a praia de Ramos, outrora intensamente usufruída. Neste caso há uma superposição de açôes, uma vez que esta área está contemplada no Programa de Despoluição da Baía de Guanabara (PDBG), o que até o momento não trouxe melhorias significativas ao controle da poluição desta área.

Finalmente, vale lembrar que as práticas adotadas, em sua grande maioria, desconsideram o papel fundamental exercido pela populaçáo atendida, que alijada das alternativas implementadas, não desempenha uma postura proativa de valorização e proteção dos sistemas de esgotos e dos corpos hídricos, mantendo-se com isso, hábitos e costumes indevidos, arraigados culturalmente, alimentados pela falta de educaçáo ambiental em saúde e em saneamento, impactando negativamente os sistemas naturais e artificiais.

\section{CONSIDERAÇÓES FINAIS}

De forma mais abrangente, observa-se que a situação nas principais cidades brasileiras indica que as condiçôes ambientais se tornaram críticas, sendo a poluição um fator limitante ao desenvolvimento de suas potencialidades. Os diversos sistemas de saneamento ainda se apresentam vulneráveis, enquanto sua eficiência e eficácia seriam a garantia das boas condiçóes de salubridade ambiental. A crescente limitação dos recursos naturais se expressa, por exemplo, no stress hídrico (relação entre disponibilidade e utilização dos recursos hídricos) indicando a necessidade de uma mudança de perspectiva como condicionante da própria sustentabilidade da sociedade e de suas cidades.

A análise e utilizaçáo de indicadores de desempenho dos sistemas de saneamento podem, além de contribuir para a elaboração de índices ecológicos de eficiência para os ecossistemas urbanos, promover de forma catalisadora o monitoramento e controle ambiental, açôes sistêmicas imprescindíveis em qualquer conjunto de intervençôes que visem à saúde ambiental. São fundamentais para garantir a vivacidade e validade de programas de saneamento, como os direcionados para as comunidades carentes. Desta forma é possível definir critérios de projetos e obras de engenharia, avaliar acertos e erros cometidos em programas, análise das alternativas e concepções adotadas. Em síntese, confirmar o desenvolvimento tecnológico a serviço da sociedade. A eficiência dos sistemas de saneamento vem se configurando como uma exigência da sociedade através de seus interesses difusos, coletivos e representativos. Os danos ambientais decorrentes de obras públicas e de deficiência na gestáo dos sistemas atualmente são objetos de Ações Civis Públicas Ambientais ${ }^{5}$ contra particulares e o próprio Poder Público, tendo como um dos autores o Ministério Público.

\footnotetext{
5 Disciplinadas pela Lei n. 7.347, de 24/07/85.
} 
Informaçôes normalmente veiculadas pelos órgãos oficiais, como: número de ligaçôes prediais; extensão de rede de distribuição de água, coleta de esgoto sanitário, drenagem; número e vazão máxima de projeto das estaçốes de tratamento, índice de tratamento, dentre outros, enquanto dados e indicadores operacionais abordam o aspecto quantitativo do nível de cobertura. Entretanto, sobre os aspectos qualitativos dos serviços estes indicadores pouco traduzem. Daí a necessidade de se estabelecer parâmetros de qualidade e índices de eficiência para avaliação da eficácia dos sistemas implantados pelos programas a fim de se obter um quadro mais elucidativo das condiçóes dos sistemas de saneamento, atuais e futuras.

A eficiência deve se referir à obtençáo dos objetivos e metas claramente propostos com o menor custo econômico e social possível. É imprescindível estabelecer uma parametrização de desempenho a fim de que esta quantificação possa qualificar a gestão, operação e controle do sistema, assim como seu planejamento estratégico. Quanto à eficácia, refere-se ao cumprimento das metas norteadas pelos princípios da universalização, equidade, integralidade, participação e controle social, gestão pública e educação ambiental, sob avaliação contínua. Isto leva a uma análise das demandas e aplicaçóes destes sistemas enquanto barreiras sanitária e ambiental. A melhoria das condiçóes sócio-ambientais deve ser a missão que deve nortear as açôes e os compromissos.

Diversos fatores são determinantes para a eficiência dos sistemas de saneamento, dentre eles destacam-se: características naturais, investimentos, qualidade dos projetos, planejamento urbano, ocupação do solo, interaçáo com outros serviços de infra-estrutura urbana, serviços de operaçáo, manutenção e conservação, aspectos psico-sociais e sócio-econômicos das populações atendidas.

Em sua essência, os projetos de saneamento, propiciam efeitos sociais e ambientais positivos. Não obstante, a não avaliação ambiental dos projetos de saneamento ou a vulnerabilidade operacional dos sistemas existentes podem trazer efeito inverso à função pelos quais foram concebidos. Estudos demonstram a necessidade de valorização dos condicionantes ambientais em nível dos projetos de saneamento, e em nível gerencial a urgência na implementação gradativa e continua, de Sistema de Gestáo Ambiental (SGA) nas empresas estaduais e municipais de saneamento.
Em ambos os casos estudos de parametrização se tornam parte constitutiva dessas iniciativas, vitais a sustentabilidade dos sistemas.

Os cidadãos devem poder ver, através dos indicadores de desempenho dos sistemas de saneamento, a medida de saúde de sua sociedade, os êxitos ou fracassos das políticas, programas e projetos adotados. Para tanto é necessária a promoção da transparência e responsabilidade nas gestóes pública e privada. Mais que instrumento de apoio à decisão no planejamento urbano a acessibilidade a estas informaçóes permite a possibilidade de pressão e cobrança por parte da sociedade, efetivando assim seu cumprimento por parte do poder público e das concessionárias.

No caso específico da Cidade do Rio de Janeiro, pelo exposto, conclui-se que o equacionamento desta problemática, enquanto um conjunto de açóes que não contemplem monitoramento, controle e fiscalização na reduçáo dos aportes de poluiçâo através de um programa contínuo de eliminação das interconexóes apresenta-se inadequado, devendo haver uma mudança de curso nas soluçóes implementadas no controle da poluição urbana dos corpos hídricos da Cidade do Rio de Janeiro.

A compreensão do problema e a proposição de alternativas técnicas fazem parte da aplicação e do próprio exercício da engenharia. O fato dos sistemas de esgotos envolverem questóes hidráulicas, eletromecânicas, construtivas, topográficas, ambientais, sociais, de hábitos e higiene, etc., requer estudos detalhados que contemplem todos estes aspectos a fim de se obterem soluçóes duradouras e sustentáveis na promoçáo de espaços saudáveis.

\section{REFERÊNCIAS BIBLIOGRÁFICAS}

ABNT/NBR 12.207. Projeto de interceptores de esgoto sanitário - Procedimento. Rio de Janeiro, $1989.3 \mathrm{p}$.

Britto, E.R. de. As galerias de águas pluviais como sistema auxiliar. In: ABES Informa. Rio de Janeiro: ABES, set/out. 2002. ano 9, n. 09/10.

Brito, F.S.R.de. Esgotos das Cidades. 1901. In: Esgotos - Parte Geral. Obras Completas de Saturnino de Brito, Rio de Janeiro: Imprensa Nacional, 1943. v. 2, p. 9-88. 
CEDAE - Plano Diretor de Esgotamento Sanitário da Região Metropolitana do Rio de Janeiro e das Bacias Contribuintes à Baía de Guanabara - Relatório Sintese. Rio de Janeiro: Serviços Técnicos de Engenharia S.A. 258 p. 1994.

CEDAE. Jornal da CEDAE. Veículo oficial de divulgação. Rio de Janeiro: Ano 1, n. 1, abril/2003.

Coaracy, V. Memórias da Cidade do Rio de Janeiro. 2. ed., Rio de Janeiro: José Olympio, 1965. p. 59215 .

La Rovere, E. L. Souza Jr., A.B.; Cantarino, A.A.A.; Kligerman, D.C., Souza, D.S.; Amaral, J.A.G.; Barata, M.M.L.; Malheiros, T.M.M. $A u-$ ditoria Ambiental do Sistema de Esgotamento Sanitário servindo a Bacia Contribuinte à Lagoa Rodrigo de Freitas e Sub-Bacia do Rio Rainha. Rio de Janeiro, operado pela CEDAE. PPE-1959. Relatório Técnico. 2001.

Dias, A.P. Análise da interconexão dos sistemas de esgotos sanitários e pluvial da Cidade do Rio de Janeiro: Valorizaçâo das coleçóes hidricas sob perspectiva sistêmica. Dissertação de Mestrado, PEAMB/ UERJ, 2003. 244 p.

FAPERJ. Sinal de alerta: Algas tóxicas ameaçam qualidade da água do rio Paraíba do Sul. Revista Nexo, n.1. Rio de Janeiro, nov. 2002.

Goldenfum, J. A.; Collischonn, W. Germano, A. Simulação e análise do funcionamento de um sistema de esgotos mistos em Porto Alegre. Simpósio Brasileiro de Recursos Hídricos, 12, Vitória. Anais 3. Vitória: ABRH, 1997. p. 229-236.

Gomes, P.M.L.; Thomas, F.R. Calhman, O.K.B. Alternativas para a Melhoria da Qualidade da Água junto a Captação da CEDAE no Rio Guandu. In: Seminário Bacia Hidrográfica do Rio Guandu - Problemas e Soluçôes. Rio de Janeiro: Comitê da Bacia Hidrográfica do Rio Guandu. UFRural, 8 p. 2002.

Kligerman, D.C. Gestão ambiental integrada: recursos hidricos, saneamento e saúde. Tese (Doutorado em Planejamento Energético) - Universidade Federal do Rio de Janeiro, UFRJ, Rio de Janeiro, $2001.314 \mathrm{f}$.
PCRJ, 2001. Secretaria Municipal de Urbanismo. Desenvolvimento humano e condiçóes de vida na Cidade do Rio de Janeiro e seus bairros. Rio de Janeiro: IPEA/PCRJ/PNUD, 26 p. Disponível em: $<$ http://www.armazemdados.rio.rj.gov.br/index.htm>. Acesso em: 29 jan. 2003. (Coleção Estudos da Cidade, n.4).

Revista Bio. Revista Brasileira de Saneamento e Meio Ambiente. Rio de Janeiro: ABES. Ano XI, n. 23, jul./set. 2002.

Revista de Engenharia do Estado da Guanabara. Rio de Janeiro: Secretaria de Obras Públicas. v. 31, n. 1, jan./mar. de 1965 .

Revista Saneamento. Revista Técnica e Informativa do DNOS. 30 Anos Ediçáo Especial. Rio de Janeiro, ano 24, n. 38, abr./jun. 1970.

Rosso, T.C.A.; D’alcantara, W.B. Análise hidráulica do sistema de esgotamento sanitário da bacia hidrográfica da lagoa Rodrigo de Freitas, Rio de Janeiro. Revista Brasileira de Recursos Hídricos, Porto Alegre, v. 11, n. 1, p. 211-222, 2006.

Rosso, T.C.A.; Dias, A.P. El Río Carioca de la ciudad de Río de Janeiro, Brasil ; Preservar su historia? Fundación Centros de Estúdios y Proyectación del Ambiente (Coord.). La Sustentabilidad Hoy. 1.ed. La Plata, Buenos Aires, Argentina: Fondo editorial Cepa. 2005. p.123-140.

Telles, P.C.S. História da Engenharia no Brasil - século XVI a XIX. 2. ed. Rio de Janeiro: Livros Técnicos e Científicos, 1984. 650 p.

Silva, B.M. Fundamentos doutrinários do projeto a ser desenvolvido conforme proposição da comunidade para o sistema de esgotos da regiáo da Barra e Jacarepaguá. Rio de Janeiro: 1983. 11 p. Texto base à proposta das Associaçóes de Moradores da Baixada de Jacarepaguá - Zonal Barra encaminhada a SEMA.

Silva, R.M. da. A luta pela água. Rio de Janeiro: CEDAE, 1988. 64 p. 